\title{
Diminuição do tempo de produção e de aclimatação de duas espécies de bambu em casa de vegetação
}

\author{
Giovanni Aquino Gasparetto \\ Marcio Jara Davalo \\ Josimara Nolasco Rondon* \\ Universidade Católica Dom Bosco \\ Avenida Tamandaré, 8000, Bairro Seminário, Fazenda Escola São Vicente \\ CEP 79117-900, Campo Grande - MS, Brasil \\ Autor para correspondência \\ josimararondon@yahoo.com.br
}

Submetido em 13/07/2012

Aceito para publicação em 20/12/2012

\section{Resumo}

A China tem investido no cultivo de bambu em território brasileiro. Porém, existe um déficit significativo de produção de mudas para construção civil, carvoaria e celulose, o que compromete parte do setor florestal. Com o intuito de contribuir para que a cadeia produtiva de bambu solucione esse problema, o objetivo deste estudo foi verificar se a aplicação de ácido indol acético (AIA) promoveria crescimento vegetal em menor tempo de cultivo. No estudo, estacas de Bambusa vulgaris e B. vulgaris var. vittata foram submetidas a dois tratamentos $(0,25 \%$ e $5,0 \%$ de AIA) e cultivadas em areia lavada em casa de vegetação. Número de folhas, crescimento caulinar, enraizamento e teor de clorofila foram investigados. Não houve diferença quanto ao crescimento caulinar, comprimento de raízes e número de folhas para ambas as espécies nos dois tratamentos $(0,25$ e $5 \%$ de AIA $)$. A variação de teores de clorofila entre as duas espécies pode servir como um parâmetro de qualidade de muda florestal quando comparada a outras espécies de bambu. Aos 43 dias, as mudas estão prontas para plantio em áreas de pleno sol. No caso das espécies aqui estudadas, o tempo médio para a muda ser comercializada é de 4 a 6 meses, sem adição de auxina. Por meio dessa técnica simples e baixo custo, vários viveiristas produzirão mudas de bambu com redução de tempo, custos e mão-de- obra.

Palavras-chave: Clorofilas; Comercialização de bambu; Crescimento caulinar; Qualidade da muda

\section{Abstract}

Reduction of time for producing and acclimatizing two bamboo species in a greenhouse. China has been investing in bamboo cultivation in Brazilian lands. However, there's a significant deficit of seedling production for civil construction and the charcoal and cellulose sectors, something which compromises a part of the forestry sector. In order to contribute so that the bamboo production chain solves this problem, this study aimed to check whether the application of indole acetic acid (IAA) could promote plant growth in a shorter cultivation time. In the study, Bambusa vulgaris and B. vulgaris var. vitatta stakes underwent two treatments $(0.25 \%$ and $5.0 \%$ of IAA) and they were grown on washed sand in a greenhouse. Number of leaves, stem growth, rooting, and chlorophyll content were investigated. There was no difference with regard to stem growth, root length, and 
number of leaves for both species in the two treatments $(0.25 \%$ and $5 \%$ IAA). The chlorophyll content variation between the two species may constitute a quality parameter of forest seedling when compared to other bamboo species. After 43 days, the seedlings are ready for planting in areas of full sun. For the species studied here, the average time to the seedling sale is from 4 to 6 months, with no addition of auxin. Using this simple and low cost technique, several nurserymen will produce bamboo seedlings with reduced time, costs, and manpower.

Key words: Chlorophylls; Marketing of bamboo; Seedling quality; Stem growth

\section{Introdução}

Bambusa vulgaris Wendl. ex Nees e B. vulgaris var. vittata McClure (Poaceae) são empregadas para diversos fins, desde simples artesanato até a produção de papel de alta resistência e produção de energia. Ecologicamente são duas espécies de grande eficiência no sequestro de gás carbônico atmosférico, em virtude de sua elevada produtividade e velocidade de crescimento (RIBEIRO, 2005).

Bambusa vulgaris var. vittata (bambu imperial, verde-amarelo, brasileiro, nativa da Malásia, é considerada a mais importante do mundo, sendo utilizada na construção de casas, principalmente na Colômbia e Equador, devido à facilidade com que os colmos são cortados e transportados, pela sua durabilidade e efeito climatizado nas habitações (ALBERTINI, 1979).

Para sua reprodução recomenda-se a estaquia, processo de propagação vegetal, no qual, pequenas porções de caules, folhas ou raízes regeneram a parte da planta, formando um novo indivíduo (LOPES; BARBOSA, 2002). A regeneração de raízes em estacas é variável de acordo com a espécie, a idade e tipo da planta, localização, nutrição e estádio fisiológico de crescimento dos ramos, época do ano, condições ambientais como luz, água, temperatura, condições edáficas, umidade, bem como os tratamentos aplicados à estaca (FANTI; PERES, 2003).

Nas estacas podem ser usados reguladores vegetais (auxinas), que aplicados exogenamente em baixas concentrações promovem, inibem ou modificam processos morfológicos e fisiológicos do vegetal.

Estacas confeccionadas a partir de caules são mais vantajosas pela fácil obtenção e disponibilidade de material e de acordo com Tofanelli et al. (2002).
Auxinas são substâncias quimicamente relacionadas com o ácido indol-3-acético (AIA), que é a auxina principal de várias plantas. Essas substâncias têm em comum a capacidade de atuar na expansão e no alongamento celular, ajudando também na divisão celular em cultura de tecidos, principalmente no enraizamento (TAIZ; ZEIGER, 2008).

O AIA é responsável pela emissão de raízes em estacas o que levou sua ampla utilização em propagação vegetativa de inúmeras espécies (VALIO, 1986). Porém, grande parte dos estudos com fitorreguladores só avaliam a eficiência no enraizamento (MORAES et al., 2011).

Com o crescente interesse pelo bambu para a produção de celulose, construção civil, e grande déficit de mudas, esse trabalho teve como objetivo verificar se a aplicação de AIA promoveria crescimento vegetal em menor tempo possível de cultivo, e consequentemente diminuição dos custos de produção e aclimatação de mudas em casa de vegetação.

\section{Material e Métodos}

A propagação de $B$. vulgaris e $B$. vulgaris var. vittata ocorreu em casa de vegetação $\left(25^{\circ} \mathrm{C}+/-3^{\circ} \mathrm{C}, 64 \%\right.$, $\left.900 \mu \mathrm{mol} . \mathrm{m}^{-2} \cdot \mathrm{s}^{-1}\right)$, pertencente ao Centro de Estudos de Tecnologias de Agronegócios (CeTeAgRo), da Fazenda Escola da Universidade Católica Dom Bosco (UCDB). Areia lavada foi utilizada como substrato, e nutrientes foram fornecidos a cada 15 dias, por meio de solução de Hoagland.

Foram realizados três tratamentos: (i) controle recebeu apenas água; (ii) AIA a 0,25\%; (iii) AIA a 0,5\%.

Durante o desenvolvimento das mudas avaliou-se o comprimento das raízes e teores de clorofila. 
O número de folhas foi observado semanalmente, sendo consideradas as folhas totalmente expandidas. As medidas de crescimento caulinar e radicular foram obtidas com régua milimetrada.

Para as análises de teores de clorofila foram utilizados $100 \mathrm{mg}$ de massa fresca (MF) de folhas verdemaduras coletadas ao final do experimento. O material foi imerso em $5 \mathrm{~mL}$ de acetona $80 \%$, em tubos escuros e vedados e mantidos em banho-maria a $65^{\circ} \mathrm{C}$ por 30 minutos e resfriados à temperatura ambiente. A leitura dos teores de clorofila foi realizada em absorbâncias de 663 e $645 \mathrm{~nm}$, respectivamente, em espectrofotômetro. O teor de clorofila total foi calculado de acordo com a equação de Arnon (1949) e Lichtenthaler (1987), com base na massa fresca (MF), expressa em $\mathrm{mg} \cdot \mathrm{g}^{-1}$.

Os dados foram submetidos à análise de variância, para comparação de médias, pelo teste de Tukey, a 5\% de probabilidade, utilizando o programa Bioestat 2.0.

\section{Resultados}

Quanto ao número de folhas, observou-se que B. vulgaris var. vittata produziu maior número médio foliar do que $B$. vulgaris independente da concentração de AIA (Figura 1).

Os valores de altura caulinar foram semelhantes não havendo diferença entre os tratamentos com AIA (Figura 2).

Quando comparado com plantas do controle, observou-se que as plantas tratadas comAIA apresentaram maior altura (aproximadamente o dobro) do que plantas do controle.

Nas duas espécies, o maior comprimento de raiz foi observado nos dois tratamentos de AIA, aos 120 dias (Tabela 1).
FIGURA 1: Número médio de folhas totalmente expandidas de plantas de Bambusa vulgaris (B v) e B. vulgaris var. vittata (B vv) após 43 e 120 dias de cultivo em casa de vegetação.

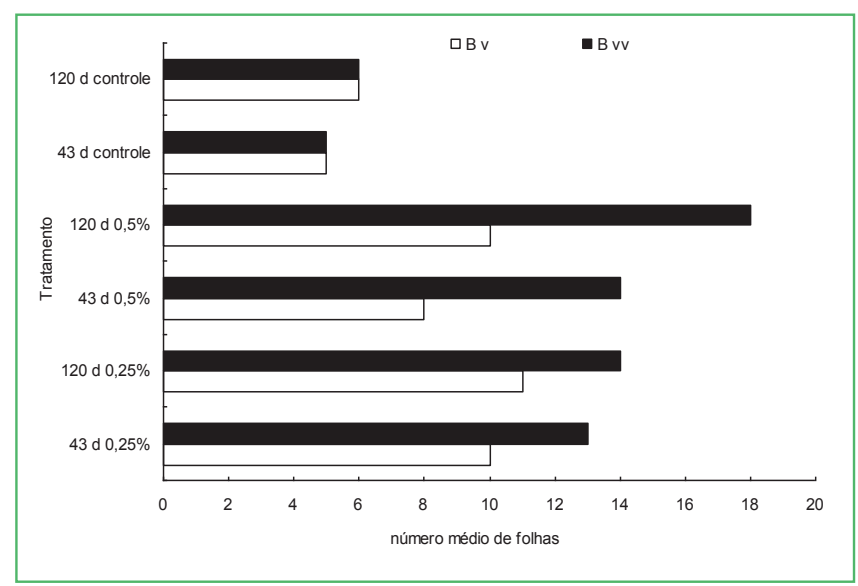

FIGURA 2: Altura caulinar de plantas de Bambusa vulgaris (B v) e B. vulgaris var. vittata $(\mathrm{B} \mathrm{vv})$, após 43 dias e 120 dias de cultivo em casa de vegetação.

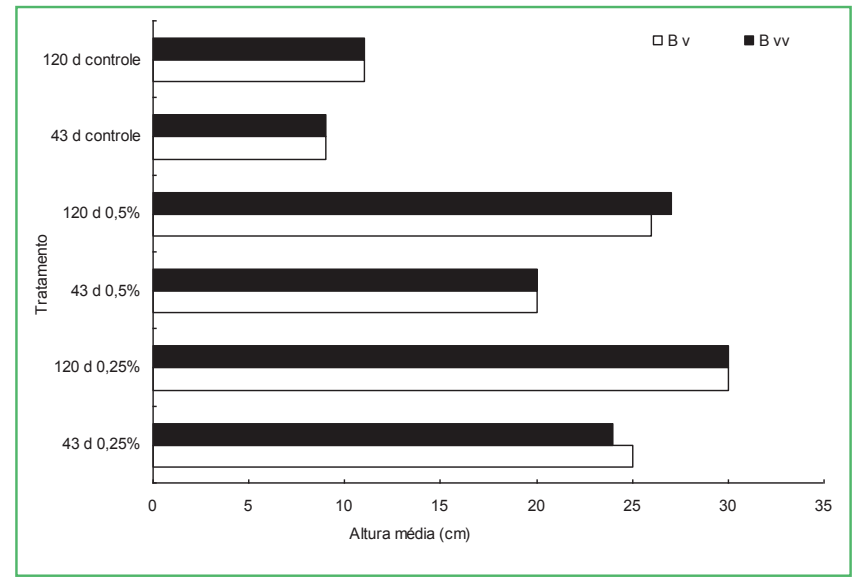

TABELA 1: Comprimento de raiz de plantas de $B$. vulgaris e B. vulgaris var. vitatta cultivadas em casa de vegetação.

\begin{tabular}{ccc}
\hline Tratamentos & 43 dias & $\mathbf{1 2 0}$ dias \\
\hline \multicolumn{3}{c}{ B. vulgaris } \\
\hline $0,25 \%$ & $5,32 \mathrm{~b}$ & $17,0 \mathrm{a}$ \\
$0,5 \%$ & $4,84 \mathrm{~b}$ & $9,0 \mathrm{~b}$ \\
Controle & $3,11 \mathrm{~b}$ & $5,0 \mathrm{c}$ \\
\hline \multicolumn{3}{|}{ B. vulgaris var. vitatta } \\
\hline $0,25 \%$ & $5,0 \mathrm{~b}, 0 \mathrm{~b}$ \\
$0,5 \%$ & $9,0 \mathrm{a}$ & $19,0 \mathrm{a}$ \\
Controle & $4,0 \mathrm{c}$ & $6,0 \mathrm{c}$ \\
CV $\%$ & 1,8 & 2,7 \\
\hline
\end{tabular}

Médias acompanhadas da mesma letra, dentro da mesma coluna, e entre as duas espécies, não diferem, pelo teste de Tukey $(\mathrm{p}>0,05)$. 
Plantas de B. vulgaris var. vitatta com 43 e 120 dias de idade tratadas com $0,25 \%$ de AIA apresentaram maior teor de clorofila total, do que plantas não tratadas (controle) (Tabela 2).

TABELA 2: Teor de clorofila a e b (mg. $\left.\mathrm{g}^{-1} \cdot \mathrm{MF}^{-1}\right)$ em folhas de B. vulgaris e B. vulgaris var. vittata cultivadas em casa de vegetação.

\begin{tabular}{|c|c|c|c|c|}
\hline \multicolumn{2}{|c|}{ B. vulgaris } & \multirow{2}{*}{$\begin{array}{c}\text { Clorofila a } \\
13,6 b\end{array}$} & \multirow{2}{*}{$\frac{\text { Clorofila b }}{5,3 \mathrm{e}}$} & \multirow{2}{*}{$\begin{array}{c}\begin{array}{c}\text { Clorofila } \\
\text { tota }\end{array} \\
18,9 \mathrm{c}\end{array}$} \\
\hline 43 dias & $0,25 \%$ & & & \\
\hline 43 dias & $0,5 \%$ & $13,0 \mathrm{~b}$ & $4,8 \mathrm{~d}$ & $17,8 \mathrm{c}$ \\
\hline 43 dias & Controle & $8,4 \mathrm{c}$ & $4,6 \mathrm{e}$ & $13,0 \mathrm{~d}$ \\
\hline 120 dias & $0,25 \%$ & $23,0 \mathrm{a}$ & $7,2 \mathrm{~d}$ & $30,2 b$ \\
\hline 120 dias & $0,5 \%$ & $18,2 \mathrm{a}$ & $5,1 \mathrm{e}$ & $23,3 c$ \\
\hline 120 dias & Controle & $9,7 \mathrm{c}$ & $5,0 \mathrm{e}$ & $14,7 d$ \\
\hline \multicolumn{5}{|c|}{ B. vulgaris var. vittata } \\
\hline 43 dias & $0,25 \%$ & $9,8 \mathrm{c}$ & $15,1 \mathrm{c}$ & $24,9 \mathrm{c}$ \\
\hline 43 dias & $0,5 \%$ & $8,7 \mathrm{c}$ & $7,8 \mathrm{~d}$ & $16,2 \mathrm{c}$ \\
\hline 43 dias & Controle & $6,7 d$ & $3,6 \mathrm{e}$ & $10,3 d$ \\
\hline 120 dias & $0,25 \%$ & $19,8 \mathrm{a}$ & $32,9 a$ & $52,7 \mathrm{a}$ \\
\hline 120 dias & $0,5 \%$ & $18,4 \mathrm{a}$ & $26,8 b$ & $45,2 b$ \\
\hline 120 dias & Controle & $8,4 \mathrm{~d}$ & $4,6 \mathrm{e}$ & $13,3 d$ \\
\hline \multicolumn{2}{|c|}{$\mathrm{CV} \%$} & & 10,9 & \\
\hline
\end{tabular}

Médias acompanhadas da mesma letra, dentro da mesma coluna, e entre as duas espécies, não diferem, pelo teste de Tukey $(\mathrm{p}>0,05)$.

A concentração de $0,25 \%$ de AIA foi satisfatória para ambas as espécies e independente do período de cultivo. Em B. vulgaris, os teores de clorofila b diferenciaram entre todos os tratamentos, independentemente da idade vegetal, porém foi sempre menor em relação à clorofila a. Ao contrário, em plantas de B. vulgaris var. vitatta, o teor clorofila $\mathrm{b}$ foi superior ao teor de clorofila a, após 120 dias. Essa maior concentração de clorofila $b$ foi observada nos tratamento $0,25 \%$ e $0,5 \%$ AIA.

Em B. vulgaris não houve interferência na concentração de clorofila $b$. Porém a idade da folha fisiologicamente madura pode ter concentrado esse tipo de clorofila. No período de análise não havia folhas velhas para fins de comparação quanto ao teor de clorofilas a e b, mostrando que as plantas estavam sempre verdes.

\section{Discussão}

O ácido indol-3-acético (AIA) regula todos os aspectos de diferenciação vascular em plantas, sendo que o transporte polar de AIA da parte aérea jovem (ALONI, 2004) para baixo através do câmbio para as pontas das raízes (ALONI et al., 2006) induz e controla a formação da madeira.

O movimento da auxina é controlado por uma família de transportadores de efluxo da membrana plasmática cujo papel principal consiste em estabelecer gradientes de concentração de auxina que atuam no crescimento de órgãos de forma assimétrica (TEALE et al., 2006).

A aplicação exógena de reguladores de crescimento, como as auxinas, promoveu o enraizamento de estacas de Dendrocalamus asper (Schult.) Heyne (SINGH et al., 2004).

O conteúdo das clorofilas das folhas representa uma característica apropriada na avaliação da aquisição de nitrogênio $(\mathrm{N})$ pelas plantas sob diferentes condições ambientais. Assim, a disponibilidade de $\mathrm{N}$ pode influenciar decisivamente na capacidade fotossintética das plantas (TAIZ; ZEIGER, 2008) refletindo no seu crescimento.

Essa variação no tipo de clorofila entre as duas espécies pode servir como um parâmetro de produtividade florestal frente a outras espécies de bambu.

Mudas de crescimento rápido em casa de vegetação, mas que ao serem transplantadas para áreas de campo, apresentam um "crescimento paralisado", resultado do teor de clorofilas. As mudas demoram a retomar o crescimento, o que termina comprometendo todo o reflorestamento de bambu.

Para $B$. vulgaris var. vitatta, o maior acúmulo de clorofila nos níveis de maior sombreamento pode ser devido à compensação da espécie à menor quantidade de radiação disponível, e pode ser uma característica de plasticidade fenotípica desenvolvida em ambiente de casa de vegetação.

Além da condição de luz, outros fatores podem influenciar o teor de clorofilas. Por exemplo, para jurema 
preta (Mimosa tenuiflora) existe uma relação negativa entre a temperatura do ar e do solo com o teor de clorofila a e uma relação positiva com a clorofila b. Essa é uma espécie pioneira, colonizadora de áreas em estado de degradação e de grande potencial de regeneração de solos erodido. Nesse estudo, os resultados não apresentaram grandes diferenças entre a relação da temperatura do ar e da temperatura do solo com as clorofilas a e b (GALVINCIO et al., 2010). Pode-se afirmar que o conteúdo de clorofila em bambus obtidos por propagação não é afetado pelo sombreamento, por isso, o resultado de maior teor de clorofila a para B. vulgaris.

Em Pinus taeda, a principal espécie florestal plantada no Sul do Brasil, a idade das mudas influenciou o enraizamento, e a maior porcentagem $(85 \%)$ foi obtida com mudas mais jovens (60 dias). As mudas de 60, 90 e 120 dias apresentaram raízes formadas de melhor qualidade, o que pode ser evidenciado pelo maior número e maior massa seca de raízes. No comprimento das três maiores raízes, não foi verificada diferença estatística entre os tratamentos; contudo, à medida que diminuiu a idade das mudas (60 e 90 dias), o comprimento das raízes aumentou $(3,0)$, em comparação com mudas de 120 e 150 dias (ALCANTARA et al. 2007).

Os valores de comprimento radicular nos tratamentos de $0,25 \%$ e $0,50 \%$ de AIA foram superiores ao tratamento controle, ao longo de todo o experimento (Tabela 1). Após 120 dias, a parte radicular de plantas de Bambusa vulgaris em tratamento de 0,25\% AIA aos 120 dias atingiram maior comprimento da raiz em relação tratamento controle, e quase o dobro do tamanho da raiz foi verificado em plantas mantidas a $0,50 \%$ de AIA (Tabela 1).

Houve diferença entre os tratamentos com AIA e o controle para o comprimento radicular, exceto nos 43 dias do B. vulgaris.

Isso significa que a resposta do uso de fitorregulador acelera a produção de raiz nos bambus, independente da concentração, conforme observado em espécies horticulturais (LEONEL; RODRIGUES, 1993), mirtilo (FISCHER et al., 2008) ou em espécies florestais (e.g. LANA et al., 2008; HOLANDA et al., 2012).
O fato da planta investir mais na formação de tecido radicular pode ser justificado pela emissão de novos indivíduos, conforme verificado em alguns momentos de avaliação, na casa de vegetação. Fachinello et al. (1994) afirmam que o AIA tem a função de acelerar a emissão de raízes, número e qualidade de raízes formadas, proporcionando o uniformidade no enraizamento.

Vale ressaltar que as diversas fases de crescimento e desenvolvimento que ocorrem ao mesmo tempo em uma planta, estão intrinsecamente relacionadas, podendo o desenvolvimento de uma parte afetar de forma positiva ou negativa o de outra (CUZZUOL et al., 1996).

A solução de Hoagland sendo uma solução nutritiva isenta de fitorregulador, apenas atuou como fonte de nutrição vegetal, visto que a areia lavada é pobre em nutrientes. O contato das estacas dos bambus utilizados foi apenas no início do experimento, sendo aplicado na região dos nós meristemáticos.

Bambusa multiplex não teve sucesso com uso de fitorreguladores, e as estacas secaram logo após sua introdução em tubetes contendo substratos de areia e terra com vermiculita $5 \%$ de ácido naftaleno acético (ANA) em casa de vegetação (Barbosa e Gomes, comunicação pessoal). Porém, foi testada a estaquia dessa espécie sem o fitorregulador, verificando o completo estabelecimento com produção de novas folhas (Rondon, comunicação pessoal).

Em um experimento com três tipos de estacas de B.vulgaris (estaca basal, primária e secundária) utilizando ácido naftaleno acético nas concentrações de 25, 50, 100 e 200 mg.L $\mathrm{L}^{-1}$, pode-se verificar os melhores níveis de enraizamento para as estacas basais com valores variando entre 20 e $60 \%$, respectivamente para a testemunha e para a concentração de $100 \mathrm{mg} . \mathrm{L}^{-1} \mathrm{de}$ ANA. Já nas estacas primárias observou-se que não houve diferença significativa entre os tratamentos, pois o enraizamento variou de 2,5 a $10 \%$, e nas estacas secundárias não aconteceu o enraizamento (AZZINI et al., 1995).

Azzini e Salgado (1993) estudaram o enraizamento de gemas primárias não brotadas e brotadas, e gemas secundárias de B. vulgaris em composto orgânico, cinzas e areia fina, e verificaram as variações de 
enraizamento (54,2 a 70,8\%; 33,3 a $54,2 \%$; 0 a $12,5 \%)$, respectivamente, com maiores variações no substrato de composto orgânico.

A aplicação de reguladores de crescimento vegetal em quantidades diminutas aumentou a produção de biomassa de Bambusa arundinacea (Retz.) Willd. (expressa em peso fresco e seco), onde $10 \mu \mathrm{M}$ de concentração de AIA foi mais eficaz no aumento da produção de biomassa (VAMIL et al., 2011).

Na presente avaliação, verificou-se que o melhor substrato para o desenvolvimento e multiplicação de $B$. vulgaris e $B$. vulgaris var. vitatta foi em areia lavada.

No caso de plantas de Guadua angustifolia obtidas de micropropagação in vitro, observou-se que se desenvolvem melhor em substrato de compostagem, recebendo solução de Hoagland a cada 15 dias (MARQUES; COSTA, 2012). Contudo, sabe-se que o aumento de raízes e velocidade de enraizamento foi promovido pelo uso do fitorregulador AIA, no momento da introdução das plantas micropropagadas em casa de vegetação.

O AIA induziu melhor enraizamento em $B$. vulgaris var. vulgaris com o maior tempo de imersão, e o ácido indolbutirico (AIB) e ANA com o menor tempo de imersão. AIA, AIB e ANA induzem melhor o enraizamento nas concentrações menores. $\mathrm{O}$ uso de ANA, nas concentrações e tempos de imersão estudados, não foi eficaz para a promoção do enraizamento das estacas de bambu. O AIA é a auxina que melhor induz o enraizamento de estacas de B. vulgaris var. vulgaris, com maior potencial de enraizamento de AIA 500 mg.L $\mathrm{L}^{-1}$ (LIMA NETO et al., 2009).

Dentre os tipos de estaca e os substratos utilizados no experimento, pode-se inferir que o jambolão pode ser propagado por meio de estacas medianas no substrato areia (LIMA et al., 2007). Essa informação corrobora com os resultados encontrados para $B$. vulgaris.

No Centro de Estudos de Tecnologia em Agronegócios (Ceteagro), atende-se por ano, cerca de dezenas de empresários que procuram no setor, formas de produzir mudas e até mesmo mudas prontas para comercializar.
Em 2006, as espécies de mudas mais vendidas e oferecidas no Brasil eram Dendrocalamus giganteus, $D$. asper, D. latiflorus, Guadua angustifolia (e as variedades colombianas), Phyllostachys pubescens, P. aurea, Bambusa vulgaris, $B$. vulgaris var. vitatta, B. tuldoides, $B$. multiplex e $B$. textilis (VASCONCELLOS, 2006). Normalmente os fornecedores de mudas de bambu são específicos, sendo que muitos viveiros e hortos florestais ainda não produzem mudas de bambu e, quando o tem, são de bambus ornamentais (gracilis ou mossô), cujo preço varia de $\mathrm{R} \$ 15,00$ a $\mathrm{R} \$ 20,00$.

Em 2012, o preço de uma muda de B. vulgaris e B. vulgaris var. vitatta custava $\mathrm{R} \$ 12,00$. Já o custo para produção e aclimatação em casa de vegetação de 1.000 mudas de qualquer uma dessas espécies fica em torno de $\mathrm{R} \$ 1.850,00$ por mês. Uma muda permanece no viveiro por no mínimo três meses antes de ser comercializada. Assim, ao contrário do que alguns viveiristas divulgam, a produção de bambu tem custo elevado. Somado a isso, deve ser considerado ainda que o tempo médio de produção das mudas varia de acordo com a espécie, e isso influencia no tempo médio em que são comercializadas. No caso das espécies aqui estudadas, o tempo médio para a muda ser comercializada é de 4 a 6 meses.

Deste modo, apresenta-se uma metodologia simples e de baixo custo, visando contribuir com os viveiristas no processo de produção de mudas de bambu em tempo reduzido. Este estudo demonstra que é possível preparar as mudas para comercialização em apenas 43 dias, além de economizar insumos e mão-de-obra.

\section{Agradecimentos}

Ao CNPq pela concessão de bolsa de iniciação científica e auxílio financeiro fornecido através do projeto Desenvolvimento Sustentável da Região CentroOeste tendo por Base a Cadeia Produtiva do Bambu.

\section{Referencias}

ALBERTINI, J. L. A. Cultura de bambu. Informe de Pesquisa, Londrina, v. 3, n. 22, p. 1-7, 1979.

ALCANTARA, G. B.; RIBAS, L. L. F.; HIGA, A. R.; RIBAS, K. C. Z; KOEHLER, H. S. Efeito da idade da muda e da estação do 
ano no enraizamento de miniestacas de Pinus taeda L. Revista Árvore, Viçosa, v. 31, n. 3, p. 399-404, 2007.

ALONI, R. The induction of vascular tissue by auxin. In: DAVIES, P. J (Ed.). Plant hormones: biosynthesis, signal transduction, action. Dordrecht: Kluwer Academic Publishers, 2004. p. 471-492. ALONI, R.; ALONI, E.; LANGHANS, M.; ULLRICH, C. I. Role of cytokinin and auxin in shaping root architecture: regulating vascular differentiation, lateral root initiation, root apical dominance and root gravitropism. Annals of Botany, Oxford, n. 97, p. 883-893, 2006.

ARNON, D. J. Copper enzymes in isolated chloroplast polyphenoloxidases in Beta vulgaris. Plant Physiology, Maryland, v. 24 , p. $1-15,1949$.

AZZINI, A.; FAHL, J. I.; SALGADO, A. L. B. Enraizamento de estacas rejuvenescidas de bambu tratadas com ácido naftaleno acético. Bragantia, Campinas, v. 54, n. 1, p. 47-50, 1995.

AZZINI, A.; SALGADO, A. L. B. Enraizamento de propágulos de bambu em diferentes substratos. Bragantia, Campinas, v. 52, n. 2, p. 113-118, 1993.

CUZZUOL, G. R. F.; GALlO, L. A.; CROCOMO, O. J. Enraizamento de cravo (Dianthus caryophyllus L.) in vitro e ex vitro. Scientia Agricola, Piracicaba, v. 53, p. 60-63, 1996.

FACCHINELlO, J. C.; HOFFMANN, A.; SANTOS, A. M. dos Amoreira-preta, framboesa e mirtilo: pequenos frutos para o sul do Brasil. In: CONGRESSO BRASILEIRO DE FRUTICULTURA, 13, 1994, Salvador. Resumos... Vol. 3. Salvador: Sociedade Brasileira de Fruticultura, 1994. p. 989-990.

FANTI, S. C.; PERES, S. C. J. G. A. Influência do sombreamento artificial e da adubação química na produção de mudas de Adenanthera pavonina L. Ciência Florestal, Santa Maria, v. 13, n. 1, p.49-56, 2003.

FISCHER, D. L. O.; FACHINELLO, J. C.; ANTUNES, L. A. C.; TOMAZ, Z. F. P.; GIACOBBO, C. L. Efeito do ácido indol butirico e do cultivar no enraizamento de estacas lenhosas de mirtilo. Revista Brasileira de Fruticultura, Jaboticabal, v. 30, n. 2, p. 285-289, 2008.

GALVÍNCIO, J. D.; PIMENTEL, R. M. M.; FERNANDES, J. G. Relação da temperatura do ar e do solo com a quantidade de clorofila a e b em jurema preta (Mimosa tenuiflora (Willd) Poiret) no semi-árido do Nordeste do Brasil. Revista Brasileira de Geografia Física, Recife, v. 3, p. 41-46, 2010.

HOLANDA, F. S. R.; VIEIRA, T. R. S.; ARAÚJO FILHO, R. N.; SANTOS, T. O.; ANDRADE, K. V. S.; CONCEIÇÃO, F. G. Propagation through cutting technique of species occurring in the lower São Francisco river in Sergipe state with different concentrations of indolbutiric acid. Revista Árvore, Viçosa, v. 36, n. 1, p. 75-82, 2012.

LANA, R. M. Q.; LANA, A. M. Q.; BARREIRA, S.; MORAIS, T. R.; FARIA, M. V. Doses do ácido indolbutírico no enraizamento e crescimento de estacas de eucalipto (Eucalyptus urophylla). Bioscience Journal, Uberlandia, v. 24, n. 3, p. 13-18, 2008.
LEONEL, S.; RODRIGUES, J. D. Efeito da época de estaquia, fitorreguladores e ácido bórico no enraizamento de estacas e portaenxertos de videira. Scientia Agricola, Piracicaba, v. 50, n. 1, p. 27-32, 1993.

LICHTENTHALER, B. K. Chlorophylls and carotenoids: pigments of photosynthetic biomembranes. Methods in Enzimology, New York, v. 148, p. 350-382, 1987.

LIMA, Y. O. U.; RITTER, M.; ALCÂNTARA, G. B.; LIMA, D. M.; FOGAÇA, L. A.; QUOIRIN, M.; CUQUEL, F. L.; BIAS, L. A. 2007. Tipos de estacas e substratos no enraizamento de jambolão. Scientia Agraria, Curitiba, v. 8, n. 4, p. 449-453, 2007.

LIMA NETO, M. C.; RIBEIRO, J. S.; NETO, E. B. Enraizamento de estacas de bambu com o uso de auxinas. Revista Acadêmica Ciências Agrárias e Ambientais, Curitiba, v. 7, n. 2, p. 175-179, 2009.

LOPES, C. L.; BARBOSA, J. G. Propagação de plantas ornamentais. Viçosa: Editora UFV, 2002. 108 p.

MARQUES, A. M.; COSTA, F. A. Produção de mudas por cultivo in vitro de Guadua anfustifolia. Scientia Agricola, Piracicaba, 2012. No prelo.

MORAES, C. P.; SOUZA-LEAL, T.; PEDRO, N. P.; MARTINE, G. A.; MORO, A. M. AIA no estímulo de brotos laterais em estacas de Dendrobium nobile Lindley (Orchidaceae). Ensaios e Ciência: Ciências Biológicas, Agrárias e da Saúde, Valinhos, v. 15, n. 2, p. 111-119, 2011.

RIBEIRO, A. S. Carvão de bambu como fonte energética e outras aplicações. Maceió: Instituto do Bambu. 2005. 140 p.

SINGH, S.; KUMAR, P.; ANSARI, S. A. A simple method for large-scale propagation of Dendrocalamus asper. Scientia Horticulturae, Amsterdam, v. 100, p. 251-255, 2004.

TAIZ, L.; ZEIGER, E. Fisiologia vegetal. 4. ed. Porto Alegre: Artmed, 2008. 819p.

TEALE, W. D.; PAPONOV, I. A.; PALME, K. Auxina em ação: o transporte de sinalização e controle do crescimento e desenvolvimento das plantas. Nature Reviews Molecular Cell Biology, London, v. 7, p. 847-859, 2006.

TOFANELLI, M. B. D.; CHALFUN, N. N. J.; HOFFMANN, A.; JUNIOR, A. C. Enraizamento de estacas lenhosas e semilenhosas de cultivares de ameixeira com várias concentrações de ácido indolbutírico. Revista Brasileira de Fruticultura, Jaboticabal, v. 24, n. 2, p. 509-513, 2002.

VALIO, I. F. M. Auxinas. In: FERRI, M. G. (Coord.). Fisiologia Vegetal. São Paulo: EPU, 1986. p. 39-72.

VAMIL, R.; ANIAT-UL-HAQ, R.; AGNIHOTRI, K.; SHARMA, R. Effect of certain plant growth regulators on the seedling survival, biomass production and proline content of Bambusa arundinacea. Science Research Reporter, Jalna, v. 1, n. 2, p. 44-48, 2011.

VASCONCELLOS, R. M. Bambúes en Brasil: una visión histórica y perspectivas futuras. 2006. Disponível em $<$ http:www. bambubrasileiro.com/arquivos>. Acesso em: 23 jun. 2012. 